Revista de
Economild
Contemporâned

\title{
O MODELO ESTRUTURA-CONDUTA- DESEMPENHO E A TEORIA EVOLUCIONÁRIA NEOSCHUMPETERIANA: UMA PROPOSTA DE INTEGRAÇÃO TEÓRICA
}

\author{
Herton Castiglioni Lopes ${ }^{a}$

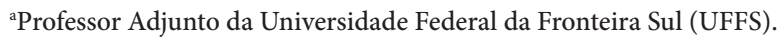 \\ Artigo recebido em 16/03/2015 e aprovado em 09/08/2016.
}

RESUMO: O texto objetiva integrar o modelo Estrutura-Conduta-Desempenho (E-C-D) e a teoria evolucionária neoschumpeteriana apresentando um enriquecedor marco teórico para analisar o desempenho industrial, bem como os fatores que afetam o desempenho das nações. Observa-se, do ponto de vista de atuação das empresas, que as variáveis presentes na estrutura, na conduta e no desempenho são altamente influenciadas pelas revoluções tecnológicas e pelo o paradigma tecnoeconômico instituído. Consequentemente, o que determina a competitividade das indústrias locais e as potencialidades dos países avançarem em suas condições de desenvolvimento é a capacidade das firmas, através de suas rotinas e inovação, de desenvolverem e incorporarem tecnologias de ponta, o que modifica sua organização e forma de atuação no mercado.

PALAVRAS-CHAVE: modelo E-C-D; teoria neoschumpeteriana; competitividade industrial; desempenho econômico.

CLASSIFICAÇÃO JEL: L10; B52; O10.

Correspondência para: Herton Castiglioni Lopes.

Contato: herton.lopes@uffs.edu.br 


\title{
THE STRUCTURE-CONDUCT-PERFORMANCE PARADIGM AND THE NEO-SCHUMPETERIAN EVOLUTIONARY APPROACH: PROPOSING A THEORETICAL INTEGRATION
}

\begin{abstract}
The paper is an attempt to integrate the Structure-Conduct-Performance model (S-C-P) and the neo-Schumpeterian evolutionary theory into a rich theoretical framework directed to analyze industrial performance and the factors that affect the performance of nations. It is observed, from the point of view of firm's action, that the variables related to structure, conduct and performance are highly influenced by technological revolutions and the techno-economic paradigm. Consequently, what determines the competitiveness of local industries and the potential of advancing countries in their development conditions is the ability of firms, by means of their routines and innovation, to incorporate and develop new technologies, which in turn modify its organization and operation of the market.
\end{abstract}

KEYWORDS: S-C-P model; neo-Schumpeterian theory; industrial competitiveness; economic performance. 


\section{INTRODUÇÃO}

Conhecer o modelo E-C-D é requisito obrigatório para economistas dedicados a análises industriais e preocupados em observar como a organização de mercado repercute sobre as estratégias das empresas e seu desempenho. Devido a sua consistência teórica, o paradigma deixou de procurar simples correlações entre concentração industrial e performance, constituindo-se como referência em modelos de análise da concorrência e estudos sobre gestão estratégica ${ }^{1}$. A amplitude de variáveis presentes e passíveis de serem incorporadas a esse modelo se tornou tão espantosa quanto sua capacidade de diagnóstico.

Por seu turno, a teoria evolucionária neoschumpeteriana tem alcançado cada vez mais relevância na atualidade. Em um momento em que a concorrência se intensifica e a flexibilidade das firmas se apresenta como principal arma frente ao rápido avanço tecnológico, a teoria ganha autoridade ao tratar da inovação como elemento-chave da competitividade, além de avançar para análises macroeconômicas que enfocam o desenvolvimento das nações ao longo do tempo. Desde que Schumpeter $(1939,1984$, 1985) demonstrou como a inovação define as condições de desenvolvimento dos países, os desdobramentos desse marco teórico não param de avançar, fazendo jus a análises microeconômicas que se desenvolveram posteriormente, assim como novas teorias sobre a dinâmica macro das inovações.

Vistos sob uma perspectiva histórica, os dois referenciais compreendem teorias da firma que se adaptam a características produtivas específicas, dependentes, portanto, do estágio de desenvolvimento tecnológico da sociedade. Ainda que a teoria neoschumpeteriana represente uma nova forma de análise, diferente da tradição da organização industrial (KUPFER, 1998) e possa ser vista como mais adequada ao paradigma das tecnologias da informação e comunicação em curso (TIGRE, 2005), sua integração ao modelo E-C-D permite análises mais precisas e de grande poder de diagnóstico. Em outras palavras, a consistência do modelo pode ser ampliada, incorporando-lhe fundamentos evolucionários, por decorrência dinâmicos e históricos do processo de transformação industrial. Da mesma forma, o paradigma converge com a teoria neoschumpeteriana, pois, nele, estão presentes diversos elementos que afetam a competitividade e a conduta (inovativa) das organizações. Com essa visão em mente, o trabalho se propõe a integrar a abordagem evolucionária neoschumpeteriana ao paradigma Estrutura-Conduta-Desempenho, propondo uma abordagem de amplo alcance na ex-

1 O modelo das cinco forças competitivas de Porter (1986), por exemplo, incorpora variáveis do paradigma E-C-D para análise da competitividade das empresas. 
plicação da dinâmica de funcionamento dos mercados e, ao mesmo tempo, contribuindo para avaliar o desempenho das firmas e sua contribuição para o desenvolvimento econômico das nações.

Espera-se que a integração teórica entre o tradicional modelo E-C-D e os fundamentos evolucionários proporcionem: i) uma análise mais precisa de como a inovação altera as estruturas de mercado, as condutas das firmas e seu desempenho; ii) a compreensão de como as firmas, mediante suas estratégias, podem preparar-se para o aproveitamento das oportunidades que se desencadeiam quando novas formas de produzir se estabelecem; iii) a observação de como as estratégias das firmas (que se constituem em rotinas e inovação) podem contribuir para o desempenho das nações; iv) o entendimento de como as políticas públicas podem, a partir de estímulos para a inovação e o progresso técnico, melhorar o desempenho das firmas e dos países e; v) uma análise integrada dos fenômenos micro e macroeconômicos que determinam o desempenho das empresas e das nações ao longo do tempo.

Com vistas a demonstrar essa interconexão teórica e a possibilidade de sinergia dessas duas teorias, a seguir, apresenta-se o modelo E-C-D com breve exposição de suas principais variáveis. Na sequência, trata-se da teoria neoschumpeteriana, dividida em duas abordagens: a teoria microeconômica evolucionária e o conceito de revoluções tecnológicas, com seus desdobramentos. Finalmente, a seção três interrelaciona as duas abordagens, demonstrando a consistência conjunta dos dois ferramentais teóricos que, embora tidos como approaches teóricos singulares, podem proporcionar ganhos inquestionáveis quando integrados.

\section{O MODELO ESTRUTURA-CONDUTA-DESEMPENHO: DEFINIÇÃO E VARIÁVEIS}

O paradigma E-C-D é um instrumento proveniente da Organização Industrial. Assim como a teoria neoschumpeteriana, seus desdobramentos provêm da insatisfação com a teoria neoclássica, que busca explicar o comportamento das firmas e funcionamento dos mercados a partir das tradicionais concepções de maximização dos lucros e equilíbrio, que não expressam os reais elementos envolvidos no processo de decisão dos empresários $^{2}$. As primeiras investigações sobre as causalidades apresentadas nos modelos E-C-D são atribuídas a E. Mason. Nos anos 1930, Mason (1939) procurou inves-

\footnotetext{
2 Exemplo disso é a pesquisa sobre a determinação de preços desenvolvida por Hall e Hicth (1986) nos anos 1930, visando justamente demonstrar que as firmas sequer tinham noção dos conceitos de receita marginal e custo marginal, precificando os produtos simplesmente a partir de uma margem adicionada aos custos de produção (mark-up).
} 
tigar a relação entre o market share das firmas e sua política de preços e produção. Concluiu que as decisões estratégicas eram afetadas por duas dimensões: pela organização interna das empresas e por sua estrutura industrial. Internamente, as condutas eram dependentes das relações interpessoais e, externamente, definidas por aspectos estruturais relativos às características do produto, aos custos e atributos de produção, ao número e às quotas de mercado de compradores e vendedores etc.

O legado de Mason coube a J. Bain, seu aluno de $\mathrm{PhD}$ que se destacou com trabalhos ricos e detalhados dentro da mesma linha teórica. Segundo Holanda Filho (1983), apesar de Mason ser o precursor nos estudos que procuravam uma ligação entre estrutura de mercado e desempenho, Bain avançou na formalização teórica do modelo, fazendo, em seu livro Industrial Organization, um estudo individual de cada um dos elementos presentes no E-C-D, para depois realizar uma análise teórico-empírica sobre suas associações. Para Lee (2007), apesar de ter sido inspirado por Mason, seu aluno utilizou uma metodologia diferenciada. J. Bain usou dados em nível de indústria enquanto Mason era a favor de estudos de caso envolvendo empresas ou setores específicos. Para Fagundes e Pondé (1998), foi mediante as contribuições de Bain (1968) que se constituiu a base teórica sobre a qual foi construído o paradigma E-C-D.

Scherer e Ross (1990) apresentam a diversidade de variáveis que podem contemplar o modelo ${ }^{3}$. Para esses autores, o paradigma proporciona o entendimento da forma como se apresentam organizadas as empresas, esclarecendo as razões de suas estratégias e desempenho. Mesmo com o grande número de variáveis, a noção de estrutura de mercado desempenha importante papel dentro do paradigma (RESENDE e BOFF, 2002; KON, 1994) e para análise que segue. Bain (1968) menciona que a estrutura se refere às características de organização das firmas que influenciam estrategicamente a natureza da competição e os preços dentro de determinado mercado. Nesse caso, uma das principais variáveis componentes do modelo é o número de empresas e seu tamanho relativo, elemento normalmente captado pelo grau de concentração de mercado. Bain (1968) afirma que o grau de concentração deve ser elemento básico nos estudos sobre indústria, já que tende a ser negativamente relacionado com a concorrência. Em termos empíricos, normalmente as medidas mais utilizadas para mensurar a concentração são a razão de concentração (Cr), o índice Herfindahl-Hirchman (HH) e o coeficiente de Theil (ET).

Não menos importante na estrutura de mercado são as barreiras à entrada, aliás, afetadas pelo nível de concorrência e concentração industrial. A preocupação com os

\footnotetext{
3 Uma síntese das variáveis do E-C-D, já incorporando a teoria neoschumpeteriana, é apresentada na Figura 1.
} 
empecilhos à concorrência teve início a partir das contribuições de J. Bain ${ }^{4}$ e Paolo Sylos-Labini nos anos $1950^{5}$. A análise das barreiras à entrada permite constatar que a competição não é definida apenas mediante análise das firmas estabelecidas. Enquanto a concorrência real se refere às firmas instaladas na indústria, a concorrência potencial trata de possíveis entrantes (BAIN, 1956), o que afeta o preço-limite nas diferentes estruturas industriais - possibilidade de as firmas elevarem seus preços acima dos custos médios sem atrair a concorrência (KON, 1994). De forma objetiva, destacam-se as seguintes barreiras: economias de escala, acesso aos canais de distribuição, desvantagens de custos independentes de escala, produto diferenciado e as barreiras institucionais (KUPFER, 2002; MARION FILHO, 1997).

A estrutura de mercado ainda pode incorporar a diferenciação dos produtos, a integração vertical e a diversificação da produção. Segundo Kon (1994, p. 87-88) a diferenciação "diz respeito à introdução, na gama de produtos de uma empresa, de uma nova mercadoria que tenha a característica de ser substituta próxima de outra anteriormente por ela produzida”. Já a integração vertical tem sido destaque em trabalhos de autores que analisam a relação entre os custos de transação e a organização interna das firmas, tais como Coase (1993) e Williamson (1999), além de obras que enfocam os custos de transação e o desempenho das nações, como os de North (1990; 2005). Finalmente, a diversificação da produção, assim como a integração vertical, é uma forma de crescimento das empresas e ocorre quando uma firma introduz um produto em um mercado do qual ela ainda não participava (KON, 1994).

Entre a estrutura de mercado e o desempenho, encontra-se a conduta das firmas. Mesmo que o sentido original do modelo seja unidirecional (da estrutura para o desempenho, perpassando pela conduta das organizações), o paradigma evoluiu, demonstrando a possibilidade de feedbacks entre as variáveis. Tratou de reconhecer o fato de as condutas afetarem a estrutura de mercado a partir de estratégias efetivas que modificam o tamanho das firmas e seu poder em relação aos concorrentes (KUPFER, 1992). Seguindo o sentido de causalidade, as condutas são, ainda, essenciais para a competitividade, assim como pressionam as políticas públicas a partir do poder de barganha exercido junto às autoridades governamentais. Objetivamente, a conduta refere-se aos padrões de comportamento que as firmas assumem para se ajustar ao

4 De acordo com Possas (1987), embora a relevância dos impedimentos à livre entrada de novas firmas já tivesse sido reconhecida por outros autores, Bain trouxe como novidade a ênfase nas barreiras como fator de fundamental importância na análise da estrutura de mercado e na formação de preços em indústrias oligopolísticas.

5 Enquanto os trabalhos de Bain focaram oligopólios diferenciados, que ocorriam devido ao processo de produção ou aos investimentos em publicidade, Labini centrou sua análise em oligopólios concentrados onde a eficiência devido à escala produtiva forma altas barreiras. 
mercado, visando, com isso, auferir melhores níveis de desempenho (LEITE, 1998). Elas englobam as diversas as ações para a determinação de preços, da produção, das características do produto, das despesas de venda, dos gastos com Pesquisa e Desenvolvimento (P\&D), etc (BEM, 1991).

Como decorrência da interação entre estrutura de mercado e conduta, tem-se o desempenho. Contudo, a performance das firmas retroage, afetando a estrutura de mercado e as estratégias escolhidas. Firmas com maior capacidade financeira, por exemplo, podem por em prática estratégias mais agressivas, sendo capazes de eliminar a concorrência e alterar toda configuração de mercado. Na análise do desempenho, Scherer e Ross (1990, p. 4) propõem uma avaliação multidimensional que engloba medidas privadas, como a eficiência das firmas (preço, eficiência produtiva e alocativa, lucros etc.), juntamente com aspectos de interesse social (emprego, distribuição de renda, salários etc.).

Finalmente, cabe relembrar que o modelo ainda contempla as condições básicas de oferta/demanda e as políticas públicas. As características da oferta (tecnologia, matérias-primas, tipo de produto etc.) e da demanda (elasticidade, preço da demanda, substitutos, crescimento da demanda etc.) podem repercutir não somente sobre o desempenho industrial, mas também sobre a estrutura e a conduta da indústria, já que definem como o aparato produtivo disponível e em modificação pode ser utilizado para criar ou atender as solicitações do mercado. Já as políticas públicas podem ser definidas como uma série de ações governamentais que afetam diretamente a indústria (quando são implementadas especificamente para o setor industrial, sendo elas as regulamentações, as leis antitruste, os impostos, os incentivos ao investimento etc.) ou indiretamente (quando são implementadas visando, por exemplo, interferir no sistema econômico, mas acabam repercutindo em determinados setores produtivos) (MARION FILHO, 1997).

\section{A TEORIA EVOLUCIONÁRIA NEOSCHUMPETERIANA}

Duas abordagens são extremamente relevantes quando se trata da teoria evolucionária neoschumpeteriana. A primeira apresenta uma análise microeconômica que enfoca a competitividade como resultado das estratégias das firmas e sua capacidade de inovação. A segunda, que admitimos ser complementar à primeira ${ }^{6}$, é uma abordagem mais agregada ao explicar o desempenho das nações a partir das revoluções tecnológicas e

\footnotetext{
6 Sobre essa complementaridade, sugere-se o texto de Lopes (2015).
} 
das oportunidades que se abrem quando novas tecnologias surgem e são apropriadas pela esfera produtiva.

No âmbito microeconômico, a abordagem neoschumpeteriana se preocupa com os desequilíbrios e com a mudança, que criam diferentes trajetórias de crescimento para as firmas. Richard Nelson e Sidney Winter (1974, 1977, 2005) são expoentes quando se trata dessa forma de abordagem, que faz paralelos entre os conceitos da biologia e da economia para desenvolver a metáfora evolucionista. Inconformados com a incapacidade da teoria tradicional em explicar o progresso das técnicas (inovações que modificam a qualidade dos fatores produtivos), os autores se propõem a "explorar qualquer ideia da biologia que pareça útil à compreensão de problemas econômicos" (NELSON e WINTER, 2005, p. 28) ${ }^{7}$.

Nelson e Winter (1974) partem da necessidade de definir algum mecanismo estável para tomada de decisão. Ao invés de comportamentos otimizadores, propõem que as firmas operam de acordo com um conjunto de regras, que chamam de rotinas ${ }^{8}$. Na teoria evolucionária, as rotinas são como os genes na biologia e definem as características básicas das firmas (organismos individuais/fenótipos). As rotinas apresentam-se de diversas formas e são classificadas em três tipos. Em primeiro lugar, estão as operacionais, que dizem respeito aos procedimentos com equipamentos ou fatores que não podem ser imediatamente modificados. Em segundo, existem as rotinas que determinam o aumento ou a redução no estoque de capital empregado. São rotinas para determinar os novos investimentos e o nível de capacidade produtiva. Enfim, existem as rotinas capazes de modificar rotinas. Ou seja, em determinados períodos, as empresas podem modificar várias das suas características e repensar toda a sua forma de operação (NELSON e WINTER, 2005).

O processo evolucionário proposto pelos autores conta com a explicação de como acontece o processo de seleção, adaptação e mudança. Nesse caso, a ideia é que as firmas com rotinas mais adaptadas são as com maior chance de sobrevivência e mais propensas ao crescimento e aquisição de grande parcela do mercado (crescimento populacional na visão da biologia $)^{9}$. A mudança acontece quando as rotinas, ou conjunto de técnicas, são postas à prova por determinados tipos de problema e precisam ser

\footnotetext{
Uma revisão crítica do conceito de rotinas e sua importância no campo organizacional foi apresentada em Becker (2004).

8 Nas palavras de Nelson e Winter (2005, p. 36): "a qualquer momento do tempo, as rotinas historicamente dadas governam as ações de uma empresa".

9 Hodgson (1997) reitera que, na teoria de Nelson e Winter, as rotinas são vistas como os genes da biologia. A seleção acontece na medida em que as rotinas mal adaptadas caem em desuso e outras, que geram lucros mais elevados, ganham espaço. O que determina as rotinas é a evolução da firma e do seu conhecimento.
} 
revistas. Então, surge a necessidade de inovação, que consiste em um processo de modificação ou ajuste (mutação) das rotinas. Por isso, a inovação pode ser compreendida como a busca pela solução de problemas que acometem no processo de produção ${ }^{10}$.

Rotinas e inovação não se apresentam como elementos contraditórios e divergentes. Pelo contrário, as rotinas resultam de um acúmulo de experiências (aprendizagem) que facilitam o desenvolvimento de novas técnicas produtivas. Existe, dessa forma, um feedback entre as rotinas e a inovação, pois, ao mesmo tempo em que a inovação cria novas rotinas, estas, ao estarem consolidadas e adaptadas a determinados contextos, acabam incentivando ou restringindo o desenvolvimento de novas práticas. Finalmente, as firmas mais aptas, ou que possuírem um conjunto de rotinas mais eficientes, terão maior lucratividade e, por consequência, maior participação no mercado (NELSON e WINTER, 1974, 1977, 2005; POSSAS, 2008; ZAWISLAK, 1996).

A teoria neoschumpeteriana enfatiza de forma categórica que a operação das firmas no mercado está sujeita a drásticas rupturas (inovações radicais) que acontecem devido ao desenvolvimento de novas tecnologias. Essas transformações são tratadas pelo conceito de revoluções tecnológicas que criam novos paradigmas, conceitos semelhantes aos desenvolvidos por Thomas Kuhn (1992) ${ }^{11}$ na filosofia da ciência. Se, no campo científico, as revoluções mudam a forma de fazer ciência consolidando novas práticas e abrindo espaço para a ciência normal, no campo econômico, as revoluções tecnológicas rompem com os antigos hábitos produtivos fazendo emergir novos arranjos e formas de produzir.

São essas rupturas radicais que geram períodos de desenvolvimento seguidos de crise e recessão econômica. Na linha de Schumpeter (1939), Christopher Freeman (1984) e Carlota Perez $(1992,2001,2004,2009)^{12}$ dedicaram esforços em compreender os ciclos a que estão sujeitas as economias capitalistas. Nesses autores, é possível observar que as ondas de desenvolvimento ${ }^{13}$, que perduram por cinco ou seis décadas, se iniciam a partir das revoluções tecnológicas que modificam o método de produzir da economia, alteram a forma de operação das firmas e demandam uma nova infraestru-

${ }^{10}$ Dosi (1988, p. 6) trata a inovação tecnológica como a "solução de problemas - por exemplo, a transformação de calor em movimento, moldar materiais de determinada maneira, produzir componentes com certa propriedade - satisfazendo, ao mesmo tempo, certos requerimentos de custo e comerciabilidade".

11 Dosi $(1988,1993)$, traçando paralelos com a filosofia da ciência, observou que, no campo econômico, as revoluções são como as científicas, conforme tratadas em Thomas Kuhn (1992).

12 Não é por acaso que Conceição (2001) trata os conceitos de revoluções tecnológicas e paradigmas tecnoeconômicos como pertencentes ao modelo "Freeman-Perez".

13 A noção de revoluções tecnológicas e sua relação com os estágios de desenvolvimento foi desenvolvida a partir dos estudos de Nikolai Kondratieff nos anos 1920. Maiores esclarecimentos podem ser encontrados em Perez (1983). 
tura produtiva e institucional. As revoluções tecnológicas podem ser definidas como "um poderoso e visível conjunto de tecnologias, produtos e indústrias novas e dinâmicas, capazes de abalar os alicerces da economia e promover uma onda de desenvolvimento de longo prazo" (PEREZ, 2004, p. 32, tradução nossa).

Para Perez (2004), uma revolução tecnológica passa por duas etapas distintas: um intervalo de instalação e outro de desprendimento, cada qual durando cerca de 20 ou 30 anos. O primeiro intervalo subdivide-se em dois períodos: um de irrupção, quando acontece um grande salto na produtividade das tecnologias relacionadas ao novo paradigma produtivo e outro chamado de frenesi, quando o comportamento frenético do capital financeiro, em busca de lucros associados a novas tecnologias, faz surgir bolhas financeiras. Com a crise, aparece a necessidade de regulamentação estatal e reestruturação institucional, que gera um intervalo de acomodação abrindo possibilidades para uma segunda etapa: a de desprendimento ou difusão, que se subdivide em uma fase de sinergia, com expansão do potencial inovativo e de mercado, e uma fase de maturidade, com oportunidades de investimento decrescentes e capital ocioso, que se movimenta em busca de maiores lucros. Ressalte-se que, nesse ponto, uma das grandes contribuições de Carlota Perez foi vincular a esfera produtiva à monetária, demonstrando como as revoluções tecnológicas se relacionam com as crises financeiras ao longo da história.

Até o momento, vivenciamos cinco revoluções: a revolução industrial; a era do vapor e das ferrovias; a era do aço e da eletricidade; a era do automóvel e da produção em massa; e a era da informática e da sociedade do conhecimento. As revoluções tecnológicas ocorrem com o surgimento de uma grande inovação, um "fator-chave" utilizado no processo produtivo e que define a direção para o desenvolvimento das novas tecnologias. A inovação radical desperta um novo potencial de evolução técnica, estimulando a imaginação de negócios de uma série de empreendedores pioneiros.

Dessas transformações surge um novo paradigma tecnoeconômico ${ }^{14}$. Trata-se de um roteiro para inovação, um guia para a decisão dos empresários, inovadores, gerentes, administradores e investidores em busca da maior eficiência (PEREZ, 2001). O paradigma é um tipo ideal de organização do sistema produtivo, o estabelecimento de um sentido do que se acredita ser a melhor opção tecnológica (PEREZ, 1983). Nas palavras de Perez, um paradigma tecnoeconômico é “[...] um modelo de prática ótima constituído por um conjunto de princípios tecnológicos e organizativos, genéricos e ubíquos, que

\footnotetext{
${ }^{14}$ Para Dosi $(1988,1993)$, o paradigma tecnoeconômico possui uma conotação sistêmica porque diz respeito a todo o conjunto de fatores que estimula e define a forma de operar das empresas. Para Conceição (2001), ao vincular-se a periodização dos ciclos longos, o conceito apresenta características mais agregativas ou macroeconômicas. Também incorpora, além da dimensão técnica, a dimensão econômica e institucional que afeta as inovações e o progresso tecnológico.
} 
representa a forma mais efetiva de aplicar a revolução tecnológica e usá-la para modernizar e rejuvenescer o restante da economia” (PEREZ, 2004, p. 41, tradução nossa).

O importante é observar que as revoluções tecnológicas abrem janelas de oportunidade para os países alavancarem seus níveis de desenvolvimento ${ }^{15}$. Para isso, contudo, é necessário observar a trajetória tecnológica de cada revolução. A trajetória se refere ao fato de grande parte das tecnologias seguirem um curso similar desde a inovação inicial até a sua maturação (PEREZ e SOETE, 1988; PEREZ, 2001, 2004). Ou seja, inicialmente, acontece uma inovação radical, determinado o aparecimento de um novo produto (tecnologia) que sustenta o desenvolvimento de uma indústria. Esse período inicial é marcado por uma sequência de inovações e é quando acontece a "otimização inicial”. Em seguida, as novas tecnologias passam por uma sequência de inovações incrementais, visando melhorar a qualidade, a produtividade e a posição dos produtores na indústria. Quando as inovações incrementais acarretam rendimentos decrescentes, o produto entra em sua fase de maturação. O período inicial, logo após a inovação radical, é tido como crucial, porque é o momento em que ocorre a aprendizagem e as possibilidades de melhor aproveitamento das técnicas em desenvolvimento.

Finalmente, enquanto a abordagem microeconômica evolucionária se detém aos mercados, firmas, estratégias e competitividade, a abordagem macroeconômica é capaz de explicar como as revoluções tecnológicas e as inovações afetam o desempenho das nações. As abordagens convergem, pois são as firmas, com sua capacidade de inovação, que se apropriam das novas tecnologias e afetam o crescimento que se manifesta no plano macroeconômico. Essa interpretação fica clara no item a seguir, que incorpora ao modelo E-C-D os desdobramentos de uma revolução tecnológica com vistas a explicar o desempenho das firmas e seus efeitos sobre o desenvolvimento das nações.

\section{A PROPOSTA DE INTEGRAÇÃO TEÓRICA}

Apesar da diversidade de variáveis, o modelo E-C-D é carente de uma abordagem que explique como acontece a inovação e o progresso técnico no interior das firmas. Da teoria tradicional, o modelo herdou atributos relativamente estáticos, principalmente

\footnotetext{
15 Abramovitz (1986) demonstra que a possibilidade de alcançar os países de ponta é maior quando o gap de produtividade entre estes e os que estão em desenvolvimento é grande. Nesse caso, a implantação de novas tecnologias nos países mais atrasados tende a amenizar as divergências de crescimento. Porém, esse não é o único elemento, pois existe ampla necessidade de capacitações sociais. Somente assim as oportunidades tecnológicas em curso serão adequadamente aproveitadas, reduzindo as diferenças produtivas. Para os países que não são precursores da revolução tecnológica, as mudanças de paradigma representam oportunidades para avançar (forging ahead) e alcançar os desenvolvidos (catching up) ou serem ultrapassados (falling behind).
} 
quando se trata da caracterização das estruturas de mercado ${ }^{16}$. Dessa forma, quando incorporada a análise neoschumpeteriana, o modelo ganha aspectos dinâmicos e evolucionários, demonstrando, de forma mais coerente, como a conduta das empresas e o processo inovativo, que contemporaneamente ocorre de forma deliberada (via esforços de P\&D) e em interação com uma diversidade de instituições (universidades, órgãos de pesquisa, redes de cooperação etc.), pode alterar a estrutura de mercado e o desempenho, interferindo nas condições de desenvolvimento das nações.

Nessa análise, as revoluções tecnológicas, gestadas em indústrias específicas, são de grande relevância, porque afetam direta e indiretamente a estrutura do mercado. No caso da concentração, o progresso técnico e as estratégias das empresas para desenvolverem ou apropriarem-se das novas tecnologias definem a forma de concorrência (competitividade) que se reflete no tamanho das organizações e em sua participação relativa de mercado. Por isso, o progresso técnico não é apenas uma condição básica de oferta, mas um importante componente estratégico que promove uma readequação produtiva capaz de afetar todos os parâmetros organizacionais. Quando se observa as estruturas de mercado nas duas últimas revoluções, os exemplos são evidentes ${ }^{17}$. Na era do petróleo, do automóvel e da produção em massa (quarta revolução tecnológica), as novas tecnologias (desenvolvidas e incorporadas pelas empresas) definiram a estrutura de mercado que se pautou pela necessidade de economias de escala, de integração vertical, de uso intensivo de energia e de materiais sintéticos - fatores que estimularam a concentração e centralização do capital. O próprio Sylos-Labini (1980) descreve como os progressos revolucionários dos meios de comunicação e transporte facilitaram o acesso a novos mercados, proporcionando o desenvolvimento de oligopólios mais estáveis. Por seu turno, a quinta revolução tecnológica e o paradigma das redes flexíveis criaram uma nova forma de organização que, ao se pautar pelo uso da microeletrônica, demandou a descentralização das atividades produtivas, a utilização de estruturas em rede, a segmentação de mercados, a cooperação entre empresas, a formação e a disseminação de clusters etc. (PEREZ, 2004).

\footnotetext{
${ }^{16}$ Não por acaso, Labini (1956, p. 25), referindo-se às estruturas de mercado, chegou a afirmar que sua "[...] análise é essencialmente estática, as relações funcionais analisadas não podem mudar as formas de mercado. Este princípio elimina da análise todas as ações dos agentes que possam modificar a estrutura, não somente tomando-as como unidades estanques, sem possibilidade de uma ligação analítica entre elas e o comportamento dos agentes [...]".

${ }_{17}$ Uma retrospectiva histórica de maior amplitude demonstraria que os paradigmas tecnológicos definem tanto a estrutura da indústria como os modelos de análise da firma. Essa interpretação pode ser encontrada em Tigre (2005).
} 
Como demonstrou Perez (2004) a partir da teoria de Schumpeter (1939, 1984, 1985), a irrupção de uma revolução tecnológica e a disseminação do progresso técnico promovem um processo de destruição criadora onde novas empresas surgem, outras desaparecem e muitas combinam novas técnicas produtivas com as antigas, modificando toda a estrutura organizacional e de mercado. Com a revolução tecnológica, o progresso técnico tende a modificar o número de compradores e vendedores, e a própria concentração de mercado, porque define a sobrevivência de algumas empresas e o desaparecimento de outras. Se a concorrência é vista como um processo dinâmico, as inovações acabam sendo as grandes responsáveis por esse fenômeno.

As novas tecnologias são ainda modificadoras das barreiras à entrada. As estratégias tecnológicas das firmas alteram a estrutura de custos, ao mesmo tempo em que se modifica a escala mínima para utilização de máquinas e equipamentos, as possibilidades de diferenciação dos produtos e o volume de recursos destinados aos investimentos iniciais. Por outro lado, o conceito de revoluções tecnológicas já demonstra como evoluem as barreiras quando novas tecnologias são desenvolvidas. Segundo Perez (2004), nos estágios iniciais das revoluções tecnológicas, as técnicas podem ser mais facilmente apropriadas pelas empresas e as barreiras tendem a ser menores tanto para as firmas como para os países que desejam utilizar as tecnologias revolucionárias. Passadas algumas décadas, a tendência é que sejam criadas propriedades intelectuais sobre as inovações através de patentes, dificultando a disseminação tecnológica e reduzindo a possibilidade de concorrência. Quando as tecnologias entram em fase de maturação, a apropriação se torna novamente mais fácil. Porém, nesse momento, a rentabilidade das inovações declina.

As novas tecnologias modificam, ainda, o escopo da integração vertical, o que se reflete na concentração de mercado e nas próprias barreiras. Williamson (1999) demonstrou que o paradigma da integração vertical é explicado a partir dos custos de transação decorrentes da utilização dos mercados. Observa o autor que, quanto maior a especificidade dos ativos e a recorrência das transações, menores os estímulos para utilização dos mercados e maior a tendência de integração vertical, já que essa forma de organização reduz os custos de transação.

Finalmente, as tecnologias desenvolvidas no âmbito da revolução em curso afetam a possibilidade de diversificação da produção e o grau de diferenciação dos produtos. A diversificação depende de como o progresso técnico viabiliza a fabricação conjunta de diversos produtos. Em outras palavras, refere-se às economias de escopo geradas pela ampliação das linhas de produtos similares. Já a diferenciação é resultado da utilização das novas tecnologias para criar novos atributos e atrair consumidores. Embora seja uma variável estrutural, vai ser altamente influenciada pela forma como as firmas utilizam-se do progresso técnico para rejuvenescer e diferenciar seus produtos da concorrência. Enquanto no modelo de produção em massa existia uma forte ten- 
dência à homogeneização de mercadorias, no paradigma da microeletrônica, a tendência é oposta, com produtos altamente diferenciados e destinados a nichos específicos de mercado (PEREZ, 2004). Quando os paradigmas se sobrepõem e as firmas incorporam novas tecnologias a antigos métodos de produção, as possibilidades de diferenciação se multiplicam ${ }^{18}$.

Se, por um lado, as revoluções tecnológicas são capazes de modificar as estruturas de mercado em sua amplitude de variáveis, sua própria ocorrência já pressupõe, por outro, a existência de significativas inovações organizacionais, seja nas empresas líderes (precursoras no desenvolvimento das tecnológicas do paradigma que se institui) ou nas seguidoras (que virão a incorporar as novas técnicas produtivas). Em outras palavras, é a conduta das empresas em conjunto com as instituições vigentes que define o novo paradigma tecnoeconômico e a própria organização dos mercados. Em clara oposição à versão tradicional do modelo E-C-D, observa-se a endogeneidade da estrutura de mercado, que se modifica a partir da coevolução das tecnologias (em criação, modificação ou disseminação) e estratégias ${ }^{19}$, alterando o grau de concentração, as barreiras à entrada, a integração vertical e a diversidade de variáveis que podem ser incorporadas à análise da organização das firmas no mercado.

Agregando-se à análise evolucionária, as condutas assumem importância mais expressiva, mesmo depois do paradigma considerar o feedback entre comportamento das firmas e estrutura de mercado. Observa-se que as estratégias são influenciadas pelas rotinas e inovação, sendo a competitividade resultado da capacidade de adequação das firmas às mutantes condições de mercado (KUPFER, 1992) ${ }^{20}$. Nesse ponto de vista, as firmas desenvolvem rotinas para pesquisa e desenvolvimento (fonte fundamental da inovação tecnológica), investimentos, ações de propaganda, fixação de preços etc. Estabelecidas pela aprendizagem (ZAWISLAK, 1996), as rotinas são elementos-chave para inovação ${ }^{21}$, que surgem com necessidade de extinção, de criação ou de readequação dos hábitos produtivos. Uma questão importante e que liga a abordagem microeconômica evolucionária com a dinâmica das revoluções tecnológicas é o fato de as rotinas e inovações terem de se disseminar pela estrutura produtiva da economia,

\footnotetext{
${ }^{18}$ A incorporação da microeletrônica à produção de automóveis é um exemplo de como um mercado inicialmente padronizado passa a ser altamente diferenciado.

19 Tais estratégias, muitas vezes, compreendem os próprios esforços e P\&D desenvolvidos pelas empresas, como demonstrou Nelson (2005).

${ }^{20}$ Kupfer (1992) estuda o processo de concorrência, partindo da premissa de que o tempo é um fator decisivo. Nesse caso, as estratégias competitivas adotadas pelas empresas não apresentam resultados imediatos e existe incerteza em relação ao futuro. Isso impede que as firmas avaliem com precisão suas estratégias, as dos concorrentes e o próprio padrão de concorrência setorial.

${ }^{21}$ Nelson e Winter (2005) demonstram que as firmas desenvolvem, também, rotinas para inovação.
} 
considerando as tecnologias em desenvolvimento e o paradigma que se estabelece. Quando as inovações e rotinas se pautam pela busca de novas tecnologias, são alteradas as técnicas produtivas, as condutas e a competitividade de mercado.

Unindo-se o modelo E-C-D à teoria evolucionária, é possível uma análise micro/ macroeconômica que explique a dinâmica de atuação das firmas no mercado, sua contribuição para o processo de desenvolvimento, bem como a importância do estado nesse processo. Nos países precursores das revoluções tecnológicas, o crescimento é impulsionado pela criação de novas técnicas ou sua rápida apropriação pelo setor produtivo, o que se manifesta em ganhos de produtividade e maiores níveis de crescimento. Nos países em desenvolvimento, que não são os precursores da revolução, a disseminação tecnológica pode ser mais lenta, implicando maiores dificuldades de utilização das grandes inovações. Então, o papel desempenhado pelo estado e suas políticas públicas deve ser exatamente o de facilitador do processo de apropriação e disseminação das tecnologias.

A esse respeito, a interpretação das revoluções tecnológicas a partir da interação entre ciência, tecnologia e estratégia das empresas (com as demais variáveis do modelo) é extremamente relevante. Rosemberg (2006), por exemplo, questiona a exogeneidade da ciência, demonstrando, com diversos exemplos, que as tecnologias e a pesquisa científica se desenvolvem a partir dos problemas observados na prática cotidiana das empresas. Dosi (1993) segue linha de raciocínio semelhante ao demonstrar que são as empresas, em sua busca incessante por lucros, o principal agente responsável pela inovação tecnológica e saltos de produtividade ${ }^{22}$. Ao fazer uma analogia entre ciência e economia - entre revoluções científicas e tecnológicas -, o autor observa, ainda, o fato de as empresas terem internalizado muitas atividades de P\&D. Para Nelson (2005), isso ocorre em função das especificidades de produção e comercialização, chegando a se tornar impossível que as práticas de $\mathrm{P} \& \mathrm{D}$ se encontrem em qualquer outra instituição que não a própria empresa ${ }^{23}$. Contudo, ainda que as revoluções tecnológicas sejam endógenas ao modo de produção, as inovações radicais não se disseminam imediata e homogeneamente pela estrutura produtiva das economias (PEREZ, 2012) ${ }^{24}$. Se muitas empresas ficam à margem das tecnologias revolucionárias, países menos desenvolvidos sofrem com a dificuldade de fazer com que seu parque produ-

${ }^{22}$ Os principais conceitos desse trabalho podem ser encontrados na apresentação da obra feita por Sicsú e Rosenthal (2006).

${ }^{23}$ Para Nelson (2005), a internalização da pesquisa por parte das empresas chega ao ponto de as mesmas serem capazes de produzir conhecimento científico genérico, sem imediata aplicação prática.

24 Análises de caso, que interpretam o desenvolvimento dos países a partir de sua capacitação tecnológica, são comuns na literatura. Perez (2012) apresenta o caso da América latina e sua relativa dificuldade de ingressar no paradigma da microeletrônica. Para o Brasil, pode-se indicar o trabalho de Arend (2015). 
tivo incorpore as tecnologias de ponta em função de sua limitada capacidade de acumulação tecnológica (BELL e PAVITT, 1993) ${ }^{25}$.

Dessa forma, tanto modelo E-C-D como a teoria neoschumpeteriana assumem que as políticas macroeconômicas têm papel importante nesse processo. Desde Keynes, a ligação entre a configuração macroeconômica e a atuação das firmas perpassa por políticas monetárias, cambiais e fiscais. Atrelado a elas e a uma série de questões sociais, políticas e econômicas, está o papel do setor público na criação de um ambiente de confiança para os investimentos produtivos. Na teoria da organização industrial, as políticas se referem à regulamentação, às leis antitrustes, aos impostos, aos incentivos para investimentos (e emprego) etc. Já na abordagem neoschumpeteriana, o destaque fica por conta de políticas de suporte à adoção de processos que se modificam pela revolução tecnológica em curso, o que inclui a criação de um aparato institucional adequado à inovação e progresso técnico. Isso significa a criação e o fortalecimento do sistema nacional de inovações ${ }^{26}$, compreendido como conjunto de instituições que podem alicerçar a inovação e a criação de rotinas que permitem às firmas apropriarem-se das novas técnicas produtivas.

Outro aspecto relevante é o fato de o desenvolvimento/apropriação de novas tecnologias (e o estabelecimento do novo paradigma tecnoeconômico) não acontecer sem a infraestrutura adequada. Na era da produção em massa, foram necessárias redes de estradas, portos, aeroportos, redes elétricas amplas, telecomunicações etc. Já na revolução da microeletrônica, foi preciso providenciar comunicação digital mundial (cabo, fibra ótica, satélites etc.), serviços eletrônicos, redes elétricas de fontes múltiplas, uso flexível de transporte físico de alta velocidade (por terra, ar e mar) etc. Se alguns desses investimentos não foram feitos diretamente pelo poder público, foram por ele induzidos através de estímulos institucionais e da criação de um marco regulatório apropriado.

${ }^{25}$ Bell e Pavitt (1993) definem capacidades tecnológicas como os recursos necessários para gerar e gerir a mudança tecnológica. Recentemente, Cimoli, Dosi e Stiglitz (2009) analisaram as diferenças de capacitações tecnológicas que se manifestam a partir das especificidades dos Sistemas Nacionais de Inovação (Leste Asiático x América Latina). Nelson (2007), por sua vez, reconhece que os ganhos de produtividade (crescimento) requerem modificação nos fatores físicos e nas tecnologias sociais; requerem que novas formas de fazer as coisas apareçam enraizadas na sociedade. Para o autor, a força motriz de catching up é a assimilação, aprender a fazer efetivamente o que os países de fronteira vêm fazendo.

${ }^{26}$ Não é por acaso que os neoschumpeterianos fazem alusão ao Sistema Nacional de Inovações (SNI) como fator determinante do processo de arranque e disseminação das inovações (CONCEIÇÃO, 2012). Nelson (2007) afirma que o Sistema Nacional de Inovações comporta um sistema financeiro forte (público e privado), uma educação primária e secundária adequada, universidades com formação de cientistas e engenheiros capazes de operar novas tecnologias, laboratórios públicos e privados de $\mathrm{P} \& \mathrm{D}$, mecanismos de incentivo à cooperação entre firmas etc. Por sua vez, Perez (1992, p. 59, tradução nossa) afirma que um sistema nacional de inovação deve ser "um conjunto de esquemas de comportamento profundamente enraizado nas instituições que abrigam os principais atores econômicos e no qual se estabelece uma rede de interação coerente e capaz de harmonizar os esforços das organizações públicas e privadas para um objetivo nacional comum". 
A relação entre a revolução tecnológica (e seus desdobramentos), a estrutura, a conduta de mercado (rotinas e inovação) e as políticas públicas vão definir o desempenho conjunto das firmas que se manifesta no plano macroeconômico em maiores ou menores níveis de crescimento. No plano micro, as firmas que melhor aproveitarem-se da revolução tecnológica a partir da criação de rotinas e inovações serão aquelas mais propensas a um desempenho superior (o que inclui preços, lucratividade, eficiência produtiva ou qualquer outra variável que seja incorporada como medida de desempenho). No plano macroeconômico, o crescimento se manifesta quando o conjunto de firmas (aparato produtivo da nação), com capacitações próprias e políticas adequadas, for capaz de desenvolver ou se apropriar das novas tecnologias. Para os países menos desenvolvidos, isso deve acontecer nos momentos em que se abrem as janelas de oportunidade ${ }^{27}$. Essas relações são apresentadas na figura a seguir.

\section{Figura 1 - Modelo E-C-D em uma dinâmica neoschumpeteriana evolucionária}

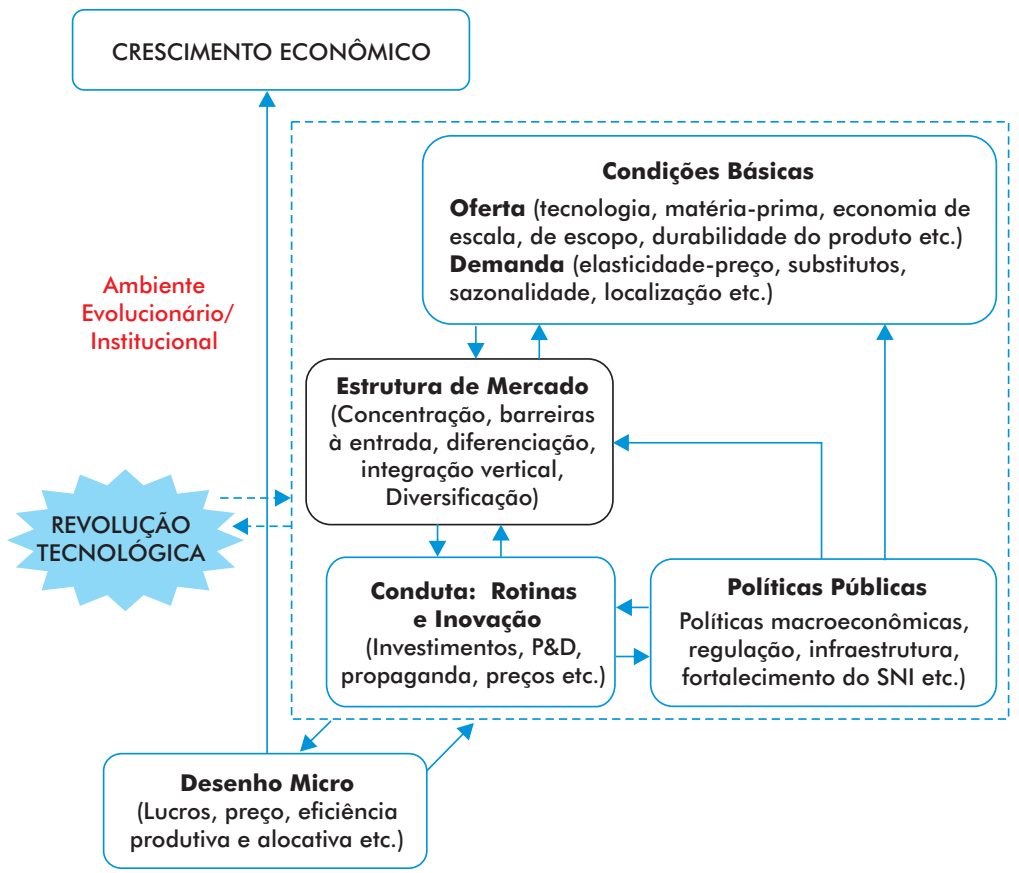

Fonte: Elaboração própria.

${ }^{27}$ Perez (2012) observa as possibilidades que se abrem aos países menos desenvolvidos com a eclosão de uma revolução tecnológica. Para os países latino-americanos na atualidade, a autora discute as potencialidades de crescimento e maior equidade social a partir da incorporação de novas tecnologias a uma estrutura produtiva rica em recursos naturais. 
O que se observa na figura é uma exposição teórico-conceitual, onde as revoluções tecnológicas, representadas por um conjunto de inovações radicais, mudam a organização e a forma de operação das firmas. A separação entre revoluções tecnológicas e conduta (estrutura de mercado e condições básicas) é apenas analítica, uma vez que as revoluções acontecem a partir de estratégias das firmas, o que altera as demais variáveis presentes no modelo. Por essa razão, destaca-se, na conduta estratégica, a importância das rotinas e da inovação, que pode acontecer a partir dos esforços de P\&D. Ainda que a separação entre revoluções tecnológicas e conduta decorra de questões teóricas, ganha relevância significativa ao se constatar que as revoluções acontecem em algumas regiões (aglomerações de empresas) e não se disseminam de forma imediata tanto entre empresas como entre nações (PEREZ, 2011).

De uma forma mais objetiva, porém, cabe sumarizar como uma revolução muda a configuração de variáveis expressas no modelo E-C-D. Tanto as condições básicas de oferta como de demanda são alteradas. No primeiro caso, as novas tecnologias interagem com técnicas antigas, assim como novos métodos produtivos se estabelecem, criando uma nova gama de produtos e serviços no mercado, porém a dinâmica da oferta modifica, também, as condições de demanda. Segundo Coriat e Dosi (2002), as políticas de demanda efetiva são fundamentais para absorção dos produtos provindos do desenvolvimento de novas tecnologias. Ao mesmo tempo, uma revolução tecnológica acaba por influenciar significativamente os consumidores, moldando suas preferências (FREEMANN, 1984) ${ }^{28}$. A revolução (em conjunto com as estratégias) modifica ainda a estrutura de mercado porque afeta a concentração industrial, seja em função do tamanho mínimo das firmas para operacionalização das novas tecnologias, seja porque muitas empresas vão desaparecer em função da dificuldade de apropriação dos novos métodos produtivos. Da mesma forma, modificam-se as barreiras à entrada, a diversificação da produção, a capacidade de diferenciação e a integração vertical. Quanto às condutas, as novas tecnologias irão afetar as rotinas no interior das firmas e o processo de inovação, que irá retroagir sobre a estrutura de mercado ao mesmo tempo em que esta, em conjunto com as estratégias, influencia no desempenho. Por fim, às políticas públicas cabe um papel determinante, pois devem ser capazes de potencializar o progresso técnico através de políticas macro e setoriais. Como o crescimento econômico é determinado pela eficiência produtiva, o desempenho das firmas a partir da utilização das novas tecnologias, sob influência da estrutura, da conduta e das políticas públicas, vai afetar a performance das nações ao longo do tempo.

\footnotetext{
${ }^{28}$ A esse respeito, Perez (2004) chega a afirmar que todo modo de vida de uma sociedade é alterado pelas novas técnicas produtivas.
} 
O processo evolucionário, que opera a partir das rotinas/condutas, demonstra que as firmas mais aptas serão aquelas com desempenho superior. Porém, é perfeitamente possível que o processo de seleção pelos mercados não leve às melhores condições produtivas (ou otimização). Ele é path dependence e pode gerar lock in a partir do predomínio de tecnologias subótimas ${ }^{29}$. Por isso, a ação do estado é indispensável, pois deve guiar a inovação e as rotinas, estimulando a adoção das tecnologias com possibilidade de melhores resultados. Além disso, deve estimular os métodos mais eficientes, criando mecanismos que proliferem as melhores técnicas. Schumpeter (1939) já havia demonstrado como a disseminação das inovações cria os ciclos econômicos. Isso significa que a coevolução de tecnologias sociais e físicas, que se manifesta no compartilhamento de rotinas produtivas (NELSON e SAMPAT, 2001; NELSON, 2007), aparece como fator indispensável ao desenvolvimento. Nesse caso, mesmo que o progresso técnico e a inovação garantam condições de monopólio às organizações mais eficientes, com o passar do tempo, as tecnologias associadas a uma revolução tecnológica devem se disseminar pela nação. Nos países em desenvolvimento, essas observações ganham ainda mais relevância, pois as políticas precisam ser mais agressivas e proporcionar a apropriação da tecnologia desenvolvida no exterior, de modo a permitir o catching up.

\section{CONSIDERAÇÕES FINAIS}

O trabalho procurou integrar o modelo E-C-D e a teoria evolucionária neoschumpeteriana. O que fica evidente quando feita a simbiose é que emerge uma rica e consistente teoria para análises micro e macroeconômicas, pois se observa como as revoluções tecnológicas e as inovações modificam as variáveis normalmente utilizadas no modelo e seus efeitos sobre a performance das nações ao longo do tempo.

Quando incorporada a teoria neoschumpeteriana ao E-C-D, demonstra-se a clara dimensão evolucionária e histórica que possui a organização das firmas no mercado. Como a tecnologia é mutante, as estruturas de mercado são altamente determinadas pelas estratégias das empresas que buscam desenvolver e apropriar-se dos novos métodos produtivos. Em outras palavras, os esforços das firmas imitadoras ou precurso-

\footnotetext{
${ }^{29}$ Exemplos de como o processo evolucionário pode determinar a sobrevivência de tecnologias menos eficientes podem ser encontradas em Arthur (1989). Nesse texto, o autor demonstra como tecnologias menos eficientes, mas com retornos crescentes, são afetadas por pequenos eventos aleatórios criando uma trajetória tecnológica difícil de ser revertida. Nessa mesma linha, ainda sugere-se os textos Hodgson (1997) e David (1985), para citar apenas alguns.
} 
ras na utilização de novas técnicas é o que vai definir a nova organização dos mercados. Se considerado o fato de as revoluções tecnológicas acontecerem em espaços bem delimitados, a eficiência das empresas para se apropriarem das inovações será determinante para o seu desempenho competitivo.

A integração teórica entre o modelo E-C-D e a teoria neoschumpeteriana contribui ainda para a melhor compreensão dos diferentes estágios de desenvolvimento em que se encontram os países. A partir da ideia de ondas longas de crescimento, observa-se que as revoluções tecnológicas tendem a se disseminar pelas nações, mas em diferentes velocidades. Quanto antes as firmas se apropriarem das novas tecnologias, maiores serão suas chances de atingir graus mais elevados de competitividade, o que pode repercutir em melhores indicadores de crescimento para as nações que se aproveitarem de forma efetiva das janelas de oportunidade abertas pela revolução em curso.

Finalmente, o conceito de revoluções tecnológicas e a necessidade das firmas desenvolverem rotinas e capacidade inovativa demonstram a importância das políticas públicas tanto para o desempenho industrial como para o crescimento econômico das nações. Os estados nacionais aparecem com o importante papel de regulamentar o ambiente macroeconômico e de fazer políticas setoriais que estimulem a inovação e o progresso técnico. Dessa forma, impedem o atraso tecnológico que pode acontecer pela fragilidade empresarial, pelo excesso de concentração de mercado ou pelo protecionismo exagerado, que repercute em um frágil sistema nacional de inovações, em um baixo nível de investimentos e na constituição de um parque industrial arcaico.

\section{REFERÊNCIAS}

ABRAMOVITZ, M. Catching up, forging ahead and falling behind. Journal of Economic History, New York, v. 46, n. 2, p. 385-406, 1986.

AREND, M. A industrialização do Brasil ante a nova divisão internacional do trabalho. Texto para Discussão, IPEA, n. 2105, 2015.

ARTHUR, W. B. Competing technologies, increasing returns, and lock-in by historical events. The Economic Journal, v. 99, n. 394, p. 116-131, mar. 1989.

BAIN, J. S. Industrial organization. New York: John Wiley, 1968.

BAIN, J. S. Barriers to new competition. Cambridge: Harvard University Press, 1956.

BELL, M.; PAVITT, K. Technological accumulation and industrial growth: contrasts between developed and developing countries. Industrial and Corporate Change, v. 2, n. 2, p. 157-211, 1993.

BEM, J. S. Estrutura - conduta - desempenho de mercado das indústrias. Revista Análise, Porto Alegre, v. 1, n. 5, p. 523-538, 1991. 
BECKER, M. C. Organizational routines: a review of the literature. Industrial and corporate change, v. 13, n. 4, p. 643-677, 2004.

CIMOLI, M.; DOSI, G.; E STIGLITZ, J. E. “The political economy of capabilities accumulation: the past and future of policies for industrial development". In: CIMOLI, M.; DOSI, G.; E STIGLITZ, J. E. (Eds.) Industrial policy and development: The political economy of capabilities accumulation. Oxford/NovaYork: Oxford University Press, 2009.

COASE, R. The nature of the firm: orgins, evolution, and development. Nova York/Oxford: Oxford University, 1993.

CONCEIÇÃO, O.A.C. Instituições, crescimento e mudança na ótica institucionalista. Porto Alegre: Fundação de Economia e Estatística Siegfried Emanuel Heuser (FEE), 2001.

CONCEIÇÃO, O.A.C. Há compatibilidade entre a "tecnologia social" de Nelson e a "causalidade vebleniana” de Hodgson? Revista de EconomiaPolítica, v. 32, n. 1 (126), p. 109-127, 2012.

CORIAT, B.; DOSI, G. “The institutional embeddedness of economic change: na appraisal of the 'evolutionary' and 'regulationist' research programmes”. In: HODGSON, G. M. (Ed.). A modern reader in institutional and evolutionary economics. London: Edward Elgar Publishing, 2002.

DAVID. P. A. Clio and the economics of QWERTY. The American Economic Review, v. 75, n. 2, p. 332-337, 1985.

DOSI, G. Sources, procedures and microeconomic effects of innovation. Journal of Economic Literature, v. 26, n. 3, p. 1120-1171, set. 1988.

DOSI, G. Technological paradigms and technological trajectories: A suggested interpretation of the determinants and directions of technical change. Research Policy, v. 22, n. 2, p. 102-103, Apr. 1993.

FAGUNDES, J.; PONDÉ, J. L. Barreiras à entrada e defesa da concorrência: notas introdutórias. Texto para Discussão, Cadernos de Estudo, Universidade Cândido Mendes, n. 1, 1998.

FREEMAN, C. Inovação e ciclos longos de desenvolvimento econômico. Ensaios FEE, v. 4, n. 1, p. 5-20, 1984.

HALL, R. L.; HITCH, C. J. A teoria dos preços e o comportamento empresarial. Literatura Econômica, [S.l.] v. 8, n. 3, p. 43-78, 1986.

HODGSON. G. M. Economia e evolução: o regresso da vida à teoria econômica. Oeiras: Celta, 1997.

HOLANDA FILHO, S. B. Estrutura industrial no Brasil: concentração e diversificação. Brasília: IPEA/INPES, 1983.

KON, A. Economia industrial. São Paulo: Nobel, 1994.

KUHN, T. S. A estrutura das revoluções científicas. 3 ed. São Paulo: Perspectiva, 1992.

KUPFER, D. Padrões de concorrência e competitividade. In: ENCONTRO NACIONAL DE ECOOMIA - ANPEC, 20, Campos de Jordão, SP, 1992.

KUPFER, D. Trajetórias de reestruturação da indústria brasileira após a abertura e a estabilização. Tese (Doutorado em Economia) - Instituto de Economia da Universidade Federal do Rio de Janeiro, Rio de Janeiro, 1998. 
KUPFER, D. "Barreiras estruturais à entrada”. In: KUPFER, D.; HASENCLEVER, L. (Orgs.). Economia Industrial: fundamentos teóricos e práticas no Brasil. Rio de Janeiro: Campus, 2002.

LABINI, P.S. Oligopólio e progresso técnico. São Paulo: Abril Cultural, 1984[1956].

LEE, C. SCP, NEIO and beyond. Working Paper Series, Nottingham University Business School, v. 5, mar. 2007.

LEITE, A. L. Concentração e desempenho competitivo no complexo industrial de papel e celulose 1987-1996. Dissertação (Mestrado em Engenharia de produção) - Universidade Federal de Santa Catarina, Santa Catarina, 1998.

MARION FILHO, P. J. A evolução e a organização recente da indústria de móveis nos Estados de Santa Catarina e Rio Grande do Sul. 1997. Tese (Doutorado em Economia) - Escola Superior de Agricultura "Luiz Queiroz" ESALQ/USP, São Paulo, 1997.

MASON, E. Price and production policies of large-scale enterprise. American Economic Review, v. 1, n. 29, p. 61-74, 1939.

NELSON, R. R.; SAMPAT, B.N. Las instituiciones como factor que regula el desempeño econômico. Revista de Economia Institucional, Bogotá, v. 2, n. 005, p 17-51, 2001.

NELSON, R.; WINTER, S. G. In search of useful theory of innovation. Research Police, v. 6, n. 1, p. 36-76, jan. 1977.

NELSON, R.; WINTER, S. G. Neoclassical vs. evolutionary theories of economic growth: critique and prospectus. Economic Journal, v. 84, n. 336, p. 886-905, 1974.

NELSON, R.; WINTER, S. G. Uma teoria evolucionária da mudança econômica. Campinas: Editora da Unicamp, 2005.

NELSON, R. R. As fontes do crescimento econômico. Campinas: Editora da Unicamp, 2005.

NELSON, R. R. Economic development from the perspective of evolutionary economic theory. Working Paper Series, Globelics, 2007.

NORTH, D. C. Institutions, institutional change and economic performance. Cambridge: Cambridge University Press, 1990.

NORTH, D. C. Understanding the process of economic change. Princeton/Oxford: Princeton University Press, 2005.

PEREZ, C. SOETE, L. "Catching up in technology: entry barriers and Windows of opportunity”. In: DOSI, G. et. al. Technical change and economic theory. Pisa: Laboratory of Economics and Management (LEM), Sant'Anna School of Advanced Studies, 1988.

PEREZ, C. Finance and technical change: a long-term view. African Journal of Science, Technology, Innovation and Development, v. 3, n. 1, p. 10-35, 2011.

PEREZ, C. Una visión para América Latina: dinamismo tecnológico e inclusión social mediante una estrategia basada en los recursos naturales. Revista Econômica, Niterói, v. 14, n. 2, p. 11-54, dez. 2012.

PEREZ, C. Cambio técnico, restructuración competitiva y reforma institucional en los países en desarrollo. El trimestre económico, México, v. 1, n. 233, p. 23-64, jan./mar. 1992. 
PEREZ, C. Cambio estructural y asimilación de nuevastecnologías en el sistema económico y social. Futures, v. 15, n. 4, p. 357-375, out. 1983.

PEREZ, C. Cambio tecnológico y oportunidades de desarollo como Blanco móvil. Revista de la CEPAL, Santiago de Chile, n. 75, p. 115-136, dez. 2001.

PEREZ, C. Revoluciones tecnológicas y capital financiero: la dinâmica de las grandes burbujas financieras y las épocas de bonanza. México: Siglo XXI, 2004.

PEREZ, C. Technological revolutions and techno-economic paradigms. Working Papers in Technology Governance and Economic Dynamics, Technology Governance, n. 20, 2009.

PORTER. M. Estratégia competitiva: técnicas para análise de indústrias e da concorrência. 14 ed. Rio de Janeiro: Campus, 1986.

POSSAS, M. L. Estruturas de mercado em oligopólio. 2 ed. São Paulo: Hucitec, 1987.

POSSAS, M. L. Economia evolucionária neoschumpeteriana: elementos para uma integração micro-macrodinâmica. Estudos Avançados, v. 22, n. 63, p. 281-305, 2008.

RESENDE, M.; BOFF, H. “Concentração industrial”. In: KUPFER, D.; HASENCLEVER, L (Orgs.). Economia industrial: fundamentos teóricos e práticas no Brasil. Rio de Janeiro: Campus, 2002.

ROSENBERG, N. Por dentro da caixa-preta: tecnologia e economia. Campinas: Editora da Unicamp, 2006.

SCHERER, F.M.; ROSS, D. Industrial market structure and economic performance. 3 ed. Chicago: Raud Mc Nally \& Co, 1990.

SCHUMPETER, J. A. Bussiness cycles. New York: McGraw-Hill Book Company, 1939, p. 461.

SCHUMPETER, J. A. Capitalismo socialismo e democracia. Rio de janeiro: Fundo de Cultura, 1984.

SCHUMPETER, J. A. Teoria do desenvolvimento econômico. São Paulo: Nova Cultural, 1985.

SICSÚ, A.B.; ROSENTHAL, D. Apresentando um texto paradigmático. Revista Brasileira de Inovação, v. 5, n. 1, jan./jun.2006.

TIGRE, P. B. Paradigmas tecnológicos e teorias econômicas da firma. Revista Brasileira de Inovação, v. 4, n. 1, jan./jun., 2005.

WILLIAMSON, O. E. The economics and transaction costs. New York: Free Press, 1999.

ZAWISLAK, P. A. Uma abordagem evolucionária para casos de atividade de inovação no Brasil. Ensaios FEE, v. 17, n.1, p. 323-353, 1996. 